The $B D J$ News section accepts items that include general news, latest research and diary events that interest our readers.

Press releases or articles may be edited, and should include a colour photograph if possible. Please direct your correspondence to the News Editor, Arveen Bajaj at the BDJ, The Macmillan Building, 4 Crinan Street, London N1 9XW or by email to bdj@bda.org

\section{Oral chemotherapy analysed}

Current practices around the use of oral chemotherapy in US cancer centres need to be improved, according to researchers from Boston. Common malignancies can be treated with oral chemotherapy - and the researchers set out to analyse the guidelines and practices used by comprehensive cancer centres for the provision of oral chemotherapy.

Variations in practice emerged in the prescribing methods, consent requests and the coordination and monitoring of treatment. They found that few of the safeguards which are routinely used for infusion chemotherapy were adopted for oral chemotherapy treatment. Most of the 42 organisations which took part in the study had no required elements for prescribing oral chemotherapy and few requested patients' written consent for off protocol prescribing.

Only one in three organisations required a clinician to note the body surface area or calculation of dose on the prescription, and only one in four required the patients' diagnosis or protocol. Nearly a quarter of the centres had no formal process for monitoring patients' adherence.

The authors conclude that "prescribing, monitoring and coordination, pharmacy practices and education of patients for oral chemotherapy vary substantially. Despite clinicians' concerns about oral chemotherapies, there is no apparent consensus among oncology professionals about safe practices for these drugs. The oncology community must define safe medication practices appropriate for oral chemotherapy, develop practice guidelines and accelerate their adoption." The study is published online at www.bmj.com.

\section{Double anniversary in Tanzania}

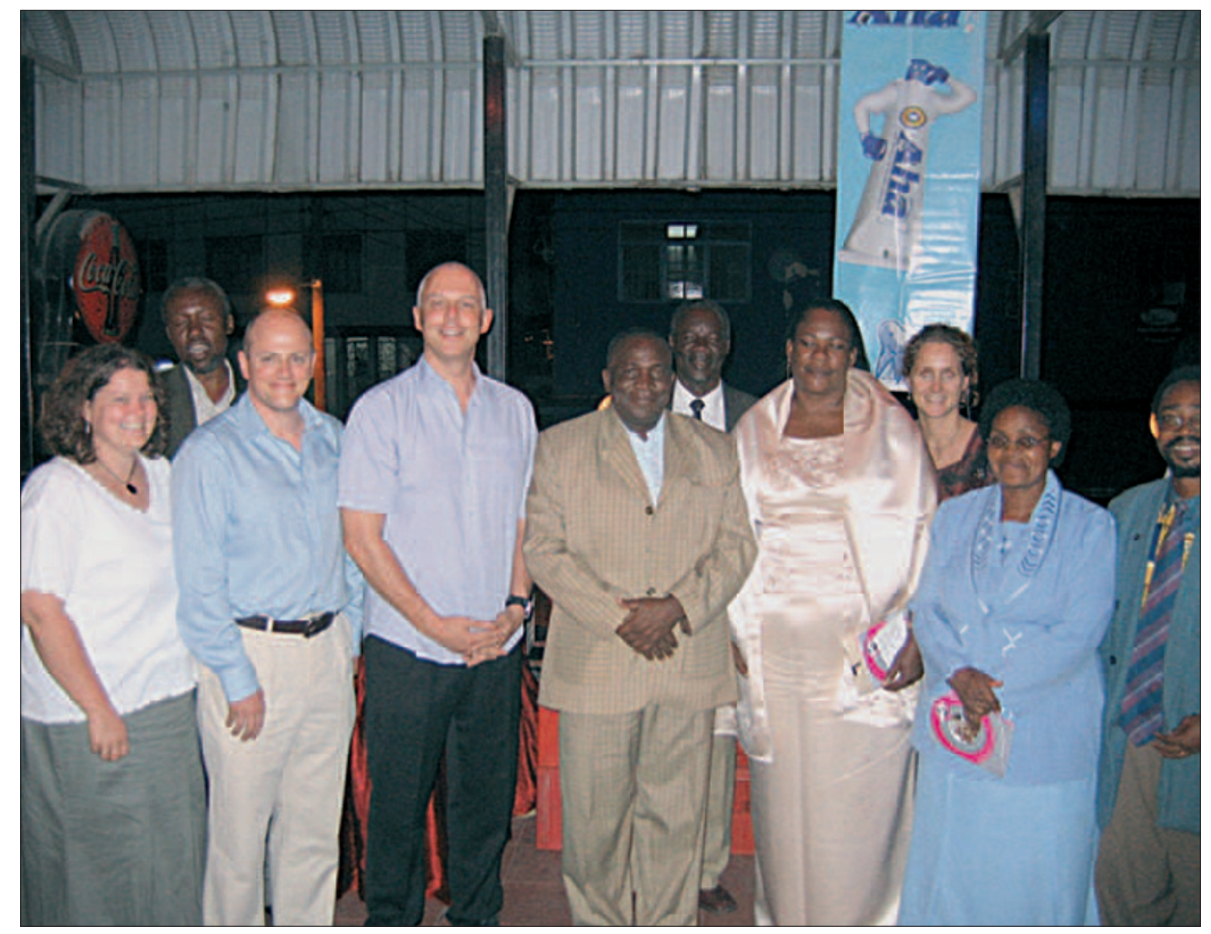

Dental charity Bridge2Aid (B2A) recently celebrated the anniversaries of two successful projects. The UK charity, who work in Mwanza, Tanzania invited Tanzanian dignitaries, advisors, friends and volunteers to celebrate two years of Hope Dental Centre (HDC), B2A's charitable dental clinic, and the Dental Volunteer Programme which trains rural health workers in emergency dentistry using UK volunteers.

HDC was heralded as a 'beacon initiative' when it opened and two years on it shows that the model of a self funding dental centre in Africa really can succeed, according to the organisation. Last year the centre generated a large proportion of B2A's income in Tanzania, funds which now cover almost all of the basic operational expenditures in Mwanza, as well as contributing a significant amount to the charity's dental and community development programmes. HDC's income means that a very high proportion of the funds raised in the UK can go directly into programme expenditure in Tanzania.

Dr lan Wilson, B2A's Executive \&t Dental Director said, "We are now reaching the point where we can employ a Tanzanian dentist to work alongside me, receive further training and help expand our capacity even further. Next year we also hope to welcome dentists for longer periods to work in the clinic and staff the dental bus which will be touring Mwanza's schools."

Over 40 dentists, nurses and hygienists have given up their time and money to work on the DVP. Many have had first time experiences of Africa through the programme and they have all been overwhelmingly positive. A good proportion of the volunteers have returned for a second and even third visit. Details of how to volunteer can be found at B2A's website www.bridge2aid.org. Pictured above, the B2A Tanzania team and trustees with Colonel Peter and Mrs Madaha, District Commissioner for Mwanza. 


\section{New dental resource launched}

Health Minister Rosie Winterton visited Rotherham recently to launch a new distance-learning package for dentists to help them play a greater role in preventing oral disease.

The CD-Rom, 'Improving Oral Health with the New Dental Contract', is aimed at dentists operating under the General Dental Contract and has been produced by Nigel Thomas, Director of Dental Public Health in Rotherham with input from both South Yorkshire dentists and national experts. Under the new General Dental Contract, primary care trusts (PCTs) have now been given new responsibilities for assessing oral health needs of local people and providing information to help prevent tooth decay.

This involves working more closely with dental practitioners to promote good oral health. The CD-Rom provides a resource for dentists to understand the impact of their role on the population and the wider responsibilities of PCTs to identify practical ways of developing a successful preventative practice. Rosie Winterton MP, said, "I have been heavily involved in improving access to dental treatment under the NHS, but we should never overlook the fact that nearly all dental disease is

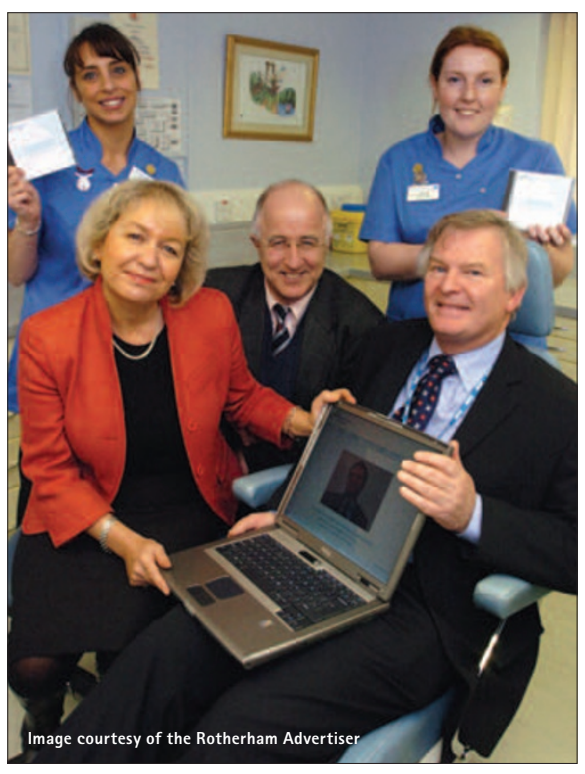

preventable. We are resolved to reducing all health inequalities, including inequalities in oral health, not just by restoring decayed teeth but by giving people the knowledge to look after their teeth and prevent further decay occurring. This is the key theme of the CD that has been launched in Rotherham and which will be going out to every dental practice in the country."

\section{First overseas President}

Professor Harold Preiskel has recently been honoured as the first overseas president of the American Prosthodontic Society (APS). The society, which is celebrating its 79th year, is holding its annual scientific meeting in Chicago this month. Professor Preiskel, who will chair the meeting, recently retired from
King's College London Dental Institute after many years of distinguished service and continues to teach postgradraduate students.

He recently set up a fund to enable postgraduate prosthodontic students at King's to represent their school at the APS event.
Dental education appointment

Dr Jonathan Bennett has been appointed by the Peninsula Dental School as Senior Lecturer in Dental Education.

A graduate of the Universities of London and Oxford in Dentistry, Science and Education, Jon Bennett has contributed extensively to both undergraduate and graduate dental courses in the UK and overseas.

He has a special interest in teaching applied basic science in dentistry supported by extensive experience of biomedical research and clinical work in the fields of Oral Surgery, Oral Medicine and Oral Pathology.

The Peninsula Dental School is a new initiative designed to take a fresh approach to the teaching and development of prospective dentists and to ensure its graduates are best prepared to rise to the oral health challenges of the future. The School will welcome its first cohort of students in September 2007 to the Batchelor of Dental Surgery (BDS) degree course.

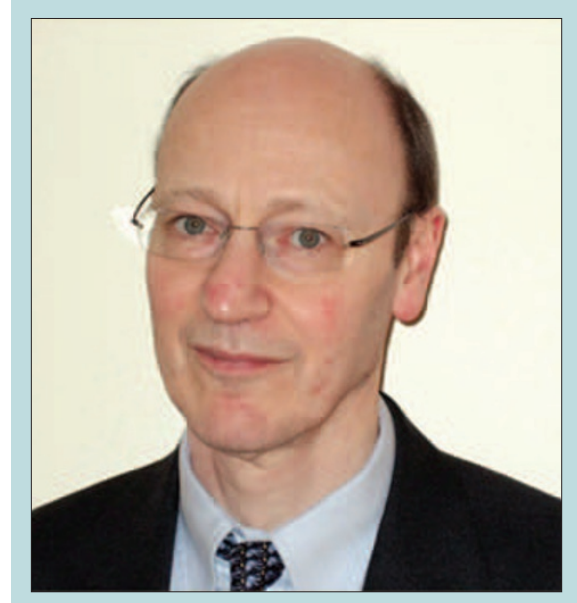




\section{New president installed}

At the recent BDHA Oral Health Conference in Harrogate, Michael Wheeler was installed as President for a two year term of office. Michael is a former Honorary Treasurer of the BDHA and has been involved in the Association's strategic management team for some years.

Michael qualified as a Dental Hygienist from the RAF Institute of Dental Health and Training Halton in 1978. While in the RAF he worked in Germany, Gibraltar and Sardinia. In addition to being a practising dental hygienist, he has been involved with the development of IT systems for dental practices and the postgraduate training of all members of the dental team.
Holding an Honours Degree in Education, Michael is Dental Development Manager for Somerset PCT and Programme Lead for Outreach Dental Training for Birmingham and Bristol Dental Schools.

In his inaugural address he said, "The future presents a real challenge for this Association. We need to develop a better understanding of members needs, especially in the changing way that dental care is provided. The introduction of mandatory CPD will also be a challenge, BDHA will be taking a leading role to ensure that it is able to meet all of your CPD needs and we have a system in place to ensure that it is properly recorded."

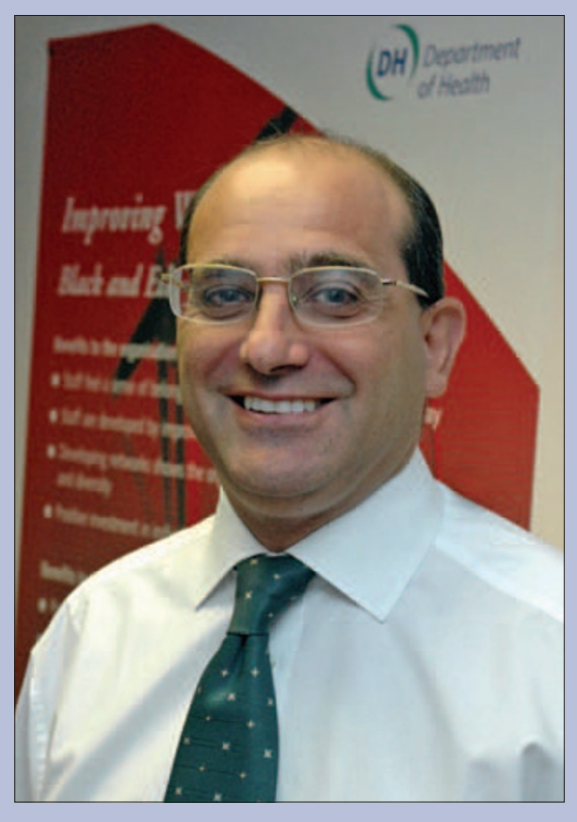

\section{Gums produce}

\section{bone-degrading substances}

Our gums' own cells produce the substances that lead to the degeneration of the jawbone, according to one of the findings in a dissertation that Dr Py Palmqvist defended at Umeå University in Sweden last month. The Swedish Research Council which supported the study, claims that the findings are important to our understanding of how inflammation leads to loosening of the teeth, arthritic rheumatism, and prostheses detaching from the body.
The dissertation shows that certain signal substances in the body, so-called cytokines, have the ability to stimulate the cells in bones to degenerate and that these cytokines are produced not only by white blood corpuscles but also by cells in the gums, called gum fibroblasts.

The production of the cytokine interleukin-6 and its closest relatives, interleukin-11 and leukemia inhibitory factor, is stimulated by certain inflammatory cytokines and is inhibited by other antiinflammatory cytokines from white

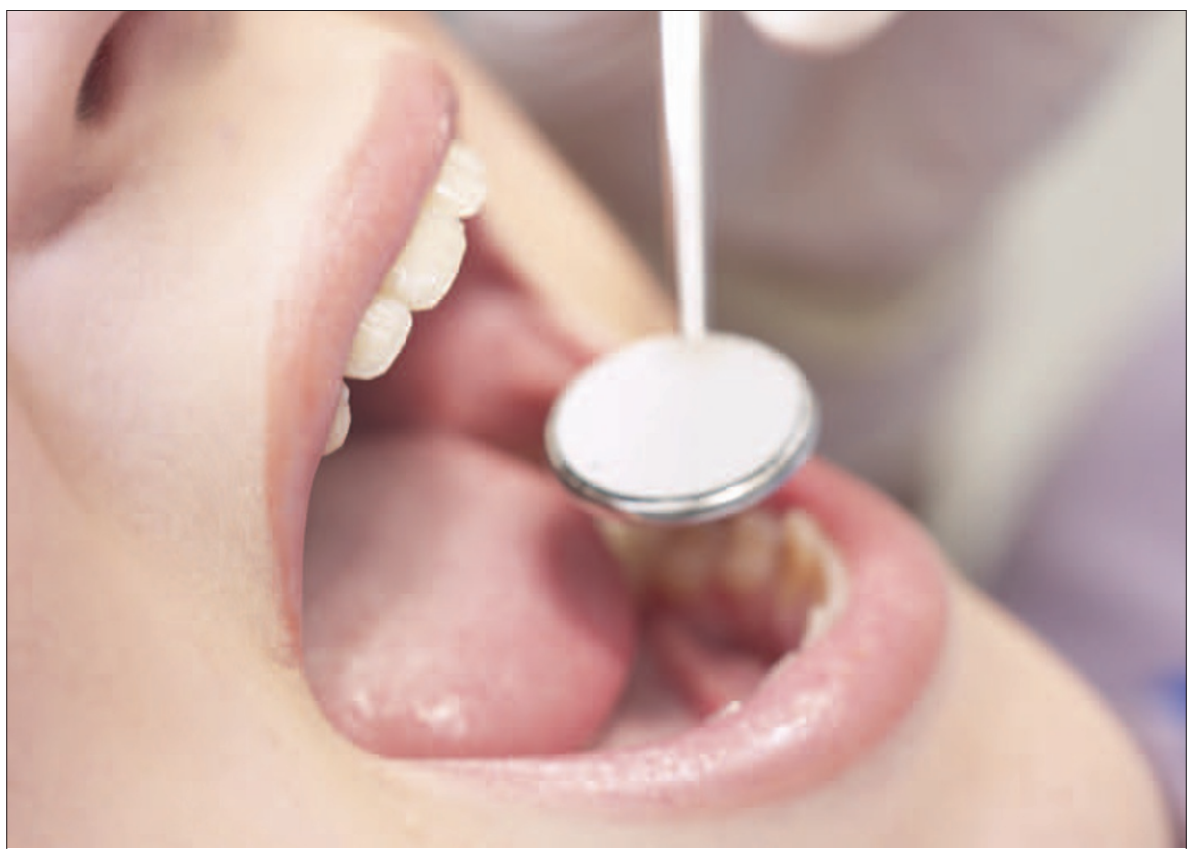

blood corpuscles. The findings show the interplay between local cells in the gums and white blood corpuscles immigrating from the blood that regulates the degradation of bone in diseases involving loosening of the teeth.

According to the study, the skeleton of a healthy adult human is constantly being renewed, with some parts degrading and being replaced by new bone, on the one hand to exchange old bone for new bone and, on the other hand, to adapt the structure of the bone to new loads. This occurs at a rate of about ten per cent of the entire bone tissue being replaced each year. In pathological conditions, the reconstruction process can be altered so that the degradation increases and the new growth cannot replace all the degenerated bone.

This occurs, for example, in most of the bones in the bodies of patients afflicted with osteoporosis as a result of changes in the amounts of sex hormones. It also occurs locally in certain parts of the skeleton where inflammatory processes are underway. In patients with inflamed gums, the inflammation process can affect the replacement of the bone around the teeth in the jaws so that the bone is lost. The teeth will then become looser and looser until they fall out.

Inflammation is also the cause of the loosening of certain implants in joints and in the skeleton. Dr Palmqvist says the findings are significant in understanding how inflammation processes lead to the degradation of bone in diseases involving loosening of the teeth, arthritic rheumatism, and the loosening of prostheses in the skeleton. Visit www.vr.se for more information. 


\section{DIARY}

February

Moving to private practice - conversion and beyond

Date: 23 February 2007

Venue: BDA, London

Tel: 02075634590

Email: events@bda.org

March

IAAFA Annual Conference and Exhibition 2007 Date: 16-17 March 2007

Venue: Marriott Hotel,Regents Park, London Email: info@iaafa.net

www.iaafa.net

\section{April}

The Society of Manchester Dental Alumni (SOMANDA) biennial meeting and reunion Date: 20 April 2007

Venue: University of Manchester

Email: carolynstylianou@ntlworld.com

May

ADI 20th Anniversary Congress

Date: 3-5 May 2007

Venue: ICC in Birmingham

www.adi.org.uk

BDA British Dental Conference

and Exhibition 2007

Date: 24-26 May 2007

Venue: Harrogate International

Centre (HIC)

Tel: 02075634590

Email: events@bda.org

June

14th Annual Congress of the Turkish Dental

Association

Date: 11-17 June 2007

Venue: Lütfi Kirdar Convention Center,

Istanbul, Turkey

www.tdbkongresi.com

113th Meeting of the American Dental Society of Europe

Date: $26-29$ June 2007

Venue: Cameron House, Loch Lomond, Scotland

Tel: 01413310088

www.adse.co.uk

\section{Link between periodontal disease and pancreatic cancer}

Researchers at the Harvard School of Public Health (HSPH) and DanaFarber Cancer Institute have found that periodontal disease is associated with an increased risk of cancer of the pancreas.

Periodontal disease is caused by bacterial infection and inflammation of the gums that over time causes loss of bone that supports the teeth; tooth loss is a consequence of severe periodontal disease. Two previous studies had found a link between tooth loss or periodontitis and pancreatic cancer, but one consisted of all smokers and the other did not control for smoking in the analysis, and therefore no firm conclusions could be drawn from these studies.

Data for the new study came from the Health Professionals FollowUp Study, which began in 1986 and includes 51,529 US men working in the health professions. Participants respond to questionnaires about their health every two years. After analysing the data, the researchers confirmed 216 cases of pancreatic cancer between 1986 and 2002; of those, 67 reported periodontal disease.

The results showed that, after adjusting for age, smoking, diabetes, body mass index and a number of other factors, men with periodontal disease had a $63 \%$ higher risk of developing pancreatic cancer compared to those reporting no periodontal disease. Lead author Dominique Michaud, Assistant Professor of epidemiology at HSPH said, "Most convincing was our finding that never-smokers had a two-fold increase in risk of pancreatic cancer."

One possible explanation for the results is that inflammation from periodontal disease may promote cancer of the pancreas. "Individuals with periodontal disease have elevated serum biomarkers of systemic inflammation, such as C-reactive protein, and these may somehow contribute to the promotion of cancer cells," she said.

Another explanation, according to Dr Michaud, is that periodontal disease could lead to increased pancreatic carcinogenesis because individuals with periodontal disease have higher levels of oral bacteria and higher levels of nitrosamines, which are carcinogens, in their oral cavity. Prior studies have shown that nitrosamines and gastric acidity may play a role in pancreatic cancer.

Michaud, senior author Charles Fuchs, a gastrointestinal oncologist at Dana-Farber, and their colleagues believe that further studies should be done to investigate the role of inflammation from periodontal disease in pancreatic cancer. However, Michaud notes that the underlying mechanisms for this association are speculative at this point. "More research is needed both to confirm this finding in other populations and also to explore the role of inflammation in this particular cancer," she said. The study was supported by grants from the National Cancer Institute and appeared in January 17, 2007 issue of the Journal of the National Cancer Institute.

\section{Orthodontic treatment has little effect on psychological health}

A major 20-year study by psychologists and dentists has cast doubt on the assumption that orthodontic treatment improves psychological well-being. The multidisciplinary team studied the longterm effects of both orthodontic treatment and lack of treatment when a need had been identified in childhood, in a paper published in The British Journal of Health Psychology last month. Over a thousand 11-12 year olds were recruited to the project in Cardiff in 1981, and their dental health and psycho-social wellbeing assessed. They were re-assessed in 1984 and 1989 and finally in 2001, then aged 31-32. Professor William Shaw of The University of Manchester, himself an orthodontist, said, "We revisited 337 of our original sample as adults, and those who had been assessed as needing orthodontic treatment in 1981 and received it had straighter teeth and were more likely to be satisfied with them. However orthodontic treatment, in the form of braces placed on children's teeth in childhood, had little positive impact on their psychological health and quality of life in adulthood."
He added that a lack of orthodontic treatment in childhood did not lead to psychological difficulties in later life for those children where a need was identified but no treatment received. "It can be concluded that, although in general participants' self-esteem increased over the 20-year period, it was not as a result of receiving braces and didn't relate to whether an orthodontic treatment need existed in 1981. This runs contrary to the widespread belief among dentists that orthodontic treatment improves psychological well-being." 


\section{Bullet proof composites developed}

Fibres used in bullet-proof vests can quadruple toughness of dental composites, according to the results of detailed engineering tests on dental composites containing glass fibers as well as the type of polyethylene fibres used in bullet-proof vests.

Vistasp Karbhari, a Professor of structural engineering at University of California San Diego, has developed fibre-reinforced polymer composites as strong, lightweight materials for aerospace, automotive, civil and marine applications. He thought, "If they work so well in highway bridges, why not dental bridges?"

In a paper, available at the Dental Materials website, Professor Karbhari and Howard Strassler, a Professor and Director of Operative Dentistry at the University of Maryland Dental School, found that the toughness of fibre-reinforced dental materials depends on the type and orientation of the fibre used.

Their report shows that braided polyethylene fibres performed the best, boosting toughness by up to 433 percent compared to the composite alone.

Many of the strength and durability tests reported in the paper are not currently required by the US Food and Drug Administration (FDA), which regulates dental composites as class II prescription devices. The agency requires eight minimum tests plus biocompatibility tests to ensure that dental composites are safe and nontoxic.

"Fibre-reinforced composites are now widely used in the aerospace and automotive industries and the experience we've gained in these applications can be applied in a more rigorous way in dentistry and medicine to tailor performance to exacting requirements," said Professor Karbhari. Dentists began using particle filled composites ten years ago as an alternative to ceramics and mercury-containing metal amalgams. Professor Strassler selected three commercially available fibre-reinforced composites for analysis.

Dental composites made with glass or polyethylene fibres are sold as pliable ribbons that dentists mold into the required shape and then harden with curing lights.

"Many reinforcing fibres can add strength and toughness to dental composites," Professor Karbhari said, "but if they are improperly aligned they could actually accelerate damage to existing teeth."

The three products tested were a 3millimeter-wide ribbon of unidirectional glass fibres, a 3-millimeter-wide ribbon of polyethylene fibres woven in a figure-of-eight stop-stitch lenoweave, and a 4-millimeter-wide ribbon of polyethylene fibres woven in a biaxial braid. The resistance to breakage and various measures of toughness of the three preparations were compared to the dental composite alone.

"All three fibre fabrics dramatically increased the durability and strength of the dental composite, but the polyethylene fibres braided in a biaxial ribbon performed best," said Professor Karbhari.

"The tests required by the FDA indicate that fibre-reinforced composites are safe, but those tests are only partially informative. Our analyses show that we can optimise these materials to match and improve performance of teeth, for greater durability, toughness, and resistance to breakage."

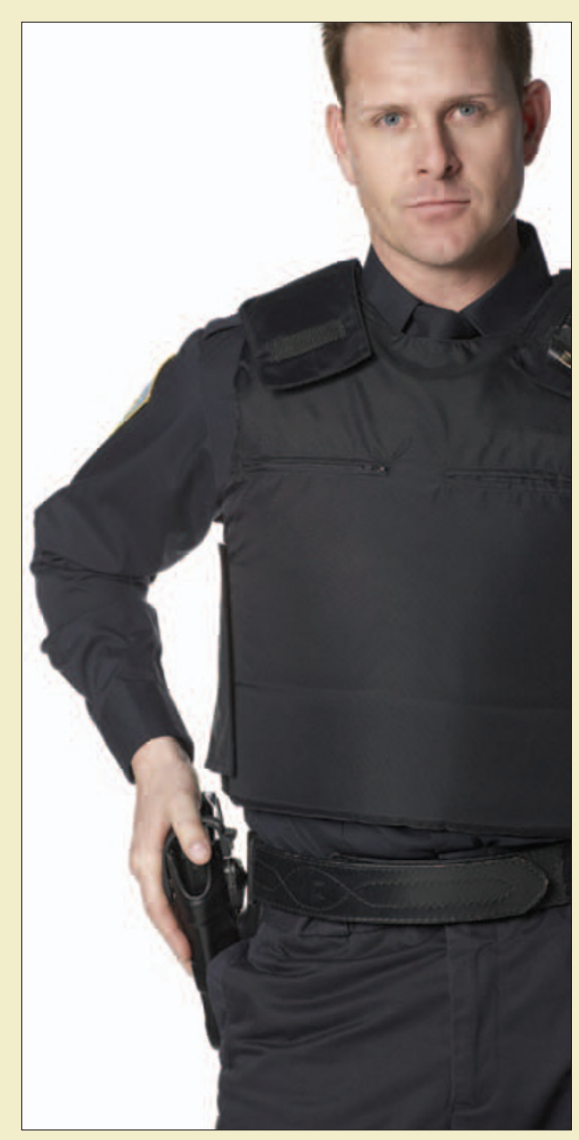

Polyethylene fibres used in bullet-proof vests can quadruple toughness of dental composites, according to the report. 